\title{
Penerapan Model Bisnis Kanvas Terhadap Bisnis Jasa Angkut Penumpang Pada PT Internasional Golden Shipping
}

\author{
Riza Kurniasari) Dwi Kartikasari²) \\ Prodi Administrasi Bisnis Terapan, Politeknik Negeri Batam \\ Jl. Ahmad Yani, Batam Centre, Batam 29461, Indonesia \\ 1) E-mail: rizakurniasari@gmail.com \\ ${ }^{2)}$ E-mail: dkartika414@gmail.com \\ Tel/HP : 081270196695
}

\begin{abstract}
Abstrak
Penelitian ini difokuskan pada PT Internasional Golden Shipping yang bergerak dibidang jasa angkut penumpang. Rumusan masalah dalam penelitian ini adalah bagaimana penerapan model bisnis kanvas pada PT Internasional Golden Shipping.

Jenis penelitian ini adalah deskriptif kualitatif yang mengarah pada pendeskripsian secara kualitatif mengenai Business Model Canvas pada PT Internasional Golden Shipping dan selanjutnya dievaluasi dengan analisis SWOT pada tiap elemennya. Metode pengumpulan data dilakukan dengan wawancara dan dokumentasi.

Hasil penelitian ini terbukti bahwa PT Internasional Golden Shipping dari segi segmentasi ekonomi lebih mengarah ke kalangan menengah atas terlihat dari value proposations keunggulan yang dimiliki perusahaan adalah satusatunya perusahaan kapal yang dapat bersandar di Johor (pasir gudang), channels yang dijalankan oleh perusahaan ini adalah menjalin hubungan baik dengan konsumennya yang dibangun dengan berhubungan secara personal sehingga konsumen dapat merasakan pelayanan yang ramah dari karyawan saat melakukan transaksi ataupun keluhan. Untuk pengahasilan yang didapat oleh perusahaan yaitu dari penjualan tiket yang dilakukan oleh SDM yang berkualitas dan didukung dengan alat operasional berupa kapal. Untuk key partnership pada perusahaan dengan keterbatasan sumber daya manusia perusahaan selalu membina dan menjga hubungan baik antar mitra bisnisnya, elemen terakhir adalah cost structure dibuktikan bahwa biaya yang paling sering dikeluarkan oleh perusahaan adalah fix costs dan variable cost.
\end{abstract}

Kata kunci: Model bisnis, kanvas, Analisis SWOT
Abstract
This research is intended to find out the Business Model Canvas, among others, customer segments, value propositions, channels, customer relationships, revenue streams, key resources, key activities, key partnerships and cost structure in PT Golden International Shipping. The research was focused on PT Golden International Shipping 
engaged in passenger transport services. Formulation of the problem in this research is how the application business model canvas at PT Golden International Shipping.

This type of research is a qualitative descriptive leads to qualitatively his work regarding Business Model Canvas at PT Golden International Shipping and further evaluated with the SWOT analysis on each element. Method of data collection is done with the interview and documentation. The results of this research proved that PT Golden International Shipping in terms of more economic segmentation leads to high circles seen from the advantages proposations value belonging to the company is the only ship that can lean in Johor (pasir gudang), channels run by the company is a good relationship with its customers that is built with a personal touch so that consumers can feel the friendly service of the employee while performing a transaction or complaints. For a living are obtained by the company from the sale of tickets is done by qualified human resources and supported with operational tools in the form of a ship. For a key partnership in the company with limited human resources company always nurture and menjga good relations between its business partner, the last element is the cost structure proved that the costs are most often issued by companies is the fix costs and variable cost

\section{Keywords: Business model, canvas, SWOT analysis.}

\section{Pendahuluan}

Pembangunan eknomi membutuhkan sarana transportasi yang cukup memadai. Tanpa adanya sarana penunjang tidak dapat diharapkan tercapainya hasil yang memuaskan dalam usaha pengembangan perekonomian suatu Negara, khususnya pada transportasi laut. Transportasi laut menrupaka modal transportasi yang menggunakan wilayah perairan sebagai jalur. Transoportasi laut ini memegang peranan penting dalam setiap kegiatan di Indonesia, khususnya di daerah-daerah yang memang berada didekat perairan, seperti laut, danau, maupun sungai. Transportasi laut sebagai sarana utama dalam pelayanan pengiriman barang dan perpindahan manusia sudah sepantasnya mendapatkan perhatian yang besar. Manajemen transportasi laut sederhana yaitu upaya agar pengiriman barang dan perpindahan manusia dapat terlaksana dengan baik. Diatur mulai dari tempat pengiriman barang dan naiknya penumpang, pengangkutan dan juga pergudangan. Pengiriman barang dan manusia melalui kapal harus memperhatikan besarnya muatan dan pemenuhan muatan agar biaya pengiriman tidak membengkak dan menghindari kecelakaan transportasi laut. Seiring dengan berjalannya waktu, banyak bisnis jasa angkut yang bermunculan sehingga persaingan di

bisnis ini semakin ketat. Untuk memenangkan persaingan, dibutuhkan suatu keunikan yang unggul atau yang sering disebut sebagai competitive advantage dalam artian bagaimana cara suatu perusahaan untuk selalu melakukan inovasi dengan mengerti keinginan dan kebutuhan konsumennya sehingga menciptakan value terhadap jasa yang akan diperjual belikan.

Salah satu perusahaan yang bergerak di bidang jasa angkut penumpang di kota Batam ini ialah PT Internasional Golden Shipping yang merupakan perusahaan pelayaran nasional yang bergerak di bidang transportasi laut khususnya kapal penumpang yang memiliki rute perjalanan luar negeri tepatnya Batam Johor (Malaysia). Perusahan ini pertama kali didirikan pada tahun 2010. Lokasi PT Internasional Golden Shipping yang berada di pusat kota memaksa perusahaan menerapkan strategi usaha dan model bisnis yang sesuai untuk menarik minat konsumen agar datang dan kembali.

Strategi usaha yang dijalankan oleh perusahaan tidak akan dapat berjalan maksimal jika tidak didasari oleh pengkajian dan perumusan model bisnis yang tepat (Chesbrough, 2006). Menurut Levy (2001), bertindak berdasarkan pada model bisnis yang salah dapat menimbulkan kerugian finansial atau kehilangan 
peluang yang sangat besar, sehingga meningkatkan potensi untuk keluar dari bisnis. Hal ini menunjukkan bahwa evaluasi model bisnis merupakan hal penting dalam dunia bisnis, tidak terkecuali pada bidang jasa angkut penumpang. Tanpa adanya model bisnis yang sesuai maka perusahaan tidak akan dapat bertahan lama.

Berdasarkan hasil uraian diatas, maka penulis ingin mengetahui sejauh mana pentingnya penerapan Bisnis Model Kanvas terhadap PT Internasional Golden Shipping. Oleh sebab itu, perlu dilakukannya kajian lebih jauh sehingga dalam penelitian ini penulis ingin mengangkat judul:

\section{"PENERAPAN MODEL BISNIS KANVAS TERHADAP BISNIS JASA ANGKUT PENUMPANG PADA PT INTERNASIONAL GOLDEN SHIPPING"}

\section{Rumusan Masalah}

Berdasarkan latar belakang tersebut rumusan masalah yang dapat diambil adalah bagaimana penerapan model bisnis kanvas pada PT Internasional Golden Shipping.

\section{Tujuan}

Berdasarkan rumusan masalah di atas, maka tujuan dari penelitian ini adalah untuk mengetahui bagiamana penerapan model bisnis kanvas pada PT Internasional Golden Shipping.

\section{Kerangka Penelitian}

Dalam penelitian ini, penulis akan mengidentifikasi dan mengevaluasi model bisnis yang diterapkan PT Internasional Golden Shipping dan merancang model bisnis baru berdasarkan pendekatan Business Model Canvas (BMC) dari Osterwalder dan Pigneur (2010). Sembilan elemen BMC terbagi atas customer segments, value propositions, channels, customer relationships, revenue streams, key resources, key activities, key partnerships, dan cost structure.

Setelah mengidentifikasi 9 elemen BMC, akan dilakukan evaluasi model bisnis dengan menggunakan SWOT.

Analisis SWOT digunakan untuk menganalisis kekuatan dan kelemahan organisasi dan mengidentifikasi peluang potensial dan ancaman. SWOT merupakan alat yang menarik karena sangat sederhana, namun dalam penggunaannya bersifat samar karena hanya memberikan sedikit arahan yang fokus pada aspek suatu organisasi untuk dianalisis. Namun ketika dikombinasikan dengan Model Bisnis Kanvas, SWOT dapat fokus menilai dan mengevaluasi elemen-elemen model bisnis. Analisis SWOT dapat memberikan dasar yang baik untuk diskusi lebih lanjut, pengambilan keputusan, dan akhirnya berinovasi seputar model bisnis (Osterwalder \& Pigneur, 2010).

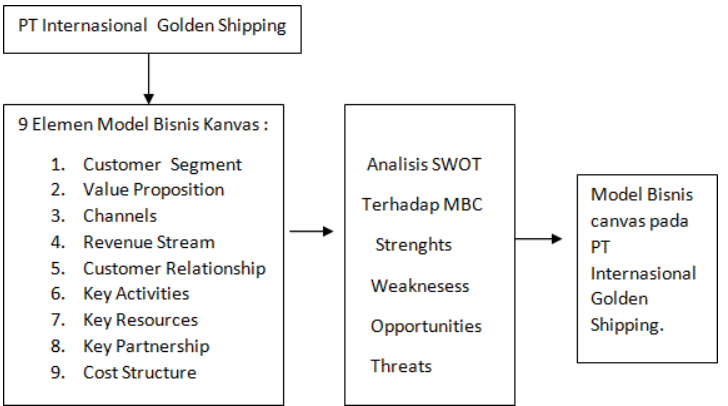

Gambar 1. Kerangka Penelitian

\section{Metode Penelitian}

\section{Jenis Penelitian}

Jenis penelitian yang digunakan adalah penelitian kualitatif deskriptif dimana peneliti ini berupaya mengumpulkan data, menganalisis secara kritis dan menyimpulkan berdasarkn fakta-fakta.

\section{Subjek dan Objek Penelitian}

Dalam penelitian ini, yang menjadi subjek penelitian adalah 5 karyawan yang terdiri dari 1 orang bagian Direktur, 1 orang keuangan, 1 orang admin, 2 orang ticketing dan 91 customer ,objek penelitiannya model bisnis kanvas PT Internasional Golden Shipping.

\section{Sumber Data}

Sumber data dalam penelitian ini diperoleh dari hasil wawancara terhadap orang yang berkompeten didalamnya, dimana hasil wawancara tersebut penulis olah dilakukan analisis. 


\section{Teknik Pengumpulan Data}

Teknik pengumpulan data dalam penelitian ini dilakukan melalui wawancara dan dokumentasi.

\section{Teknik Analisis Data}

Teknik analisis data dalam penelitian ini menggunakan teknik analisis deskriptif yaitu dengan mendeskripsikan Sembilan elemen model bisnis kanvas dan di evaluasi menggunakan analisis SWOT.

\section{Hasil Penelitian dan Pembahasan}

Pada bagian ini akan dijelaskan mengenai deskripsi dari Sembilan elemen dalam model bisnis kanvas pada PT Internasional Golden Shipping.

\section{A. Analisis Sembilan elemen bisnis kanvas}

\section{Customer segments}

Menurut jenis-jenis customer segment yang dikemukakan oleh Osterwalder (2010), Customer Segment PT Internasional Golden Shipping (PT IGS) ini termasuk dalam jenis segmented, untuk melayani pelanggan yang diklasifikasi lagi berdasarkan kebutuhan dan permasalahan mereka. Dari segi ekonomi, konsumen jasa angkut ini tentunya lebih mengarah ke kalangan menengah keatas, yang terlihat dari jumlah yang harus dibayar konsumen dalam sekali memakai jasa angkut ini sebesar +/- Rp340.000,-per penumpang (PP). Selain itu, jika dilihat dari lokasi perusahaan ini terletak di kawasan yang cukup strategis di pusat kota di mana mudah ditemukan oleh konsumen.

\section{Value Propositions}

Agar dapat terus bertahan di tengah persaingan antar pelayaran maka value proposition menjadi penentu suatu keberhasilan dalam bisnis jasa ini. Adapun value proposition saat ini adalah terkaitnya tentang kualitas pelayanan yang baik dalam persaingan pelayaran yang menjadi modal utama atau keunggulan dari bisnis jasa angkut ialah dimana PT Internasional Golden Shipping satu-satunya yang dapat memberikan pelayanan transportasi dari Batam- Johor (pasir gudang) di Batam center dan memberikan fasilitas bus untuk penumpang yang ingin pergi ke Kuala Lumpur. Quality Service menjadi nilai lain yang ditawarkan oleh perusahaan kepada para konsumennya karena perusahaan sangat memperhatikan sekali kualitas dari pelayanannya dalam menarik konsumen, seperti kebersihan, keamanan, kenyamanan, kerapian, kesopanan karyawan terhadap konsumen dan ketepatan waktu jam keberangkatan kapal yang sudah ditentukan. Dilihat dari elemen yang terdapat pada value propositions:

\section{a. Performance}

Pada perusahaan ini dilihat dari kinerja karyawan, penulis mengatakan bahwa karyawan sangat baik dalam melakukan pelayanan terhadap konsumennya dan sangat rajin saat bekerja serta dari segi jasa bisa dilihat dari kualitas maupun harganya. Adapula cara perusahaan untuk mempertahankan konsumennya disetiap kesempatan perusahaan selalu memberikan bingkisan pada saat hari besar (Idul Fitri) ataupun voucher ticket kapal kepada pelanggan tetapnya.

\section{b. Brand}

Merk yang dijual adalah tiket kapal yang rata-rata sudah banyak dikenal oleh konsumen dan satu-satunya perusahaan yang menjual tiket ke pasir gudang, Saat ini banyaknya konsumen yang memilih untuk menggunakan jasa kapal yang bersandar di pasir gudang dikarenakan mempermudah peloncong atau orang yang ingin bekerja masuk ke Negara Malaysia, pengawasan di imigrasi pasir gudang lebih memudahkan mereka masuk dibandingkan di Situlang laut. Dan hal itulah yang membuat para konsumen lebih banyak memilih jasa angkut perusahaan ini.

\section{c. Price}

Harga yang diberikan perusahaan ke konsumen yaitu Rp.340.000/ penumpang. Dikatakan terjangkau karena apabila harga sangat tinggi kemungkinan konsumen minat konsumen menggunakan jasa dari perusahaan ini sepi.

\section{d. Accessibility}

Tidak semua orang mampu membeli jasa yang 
dipasarkan dikarenakan perbedaan perekonomian setiap orang dan konsumen mengatakan bahwa mengenai harga pada diri masing-masing orang berbeda-beda, Meskipun begitu, semua orang dapat mengakses jasa ini.

\section{Channels}

Channels merupakan media suatu perusahaan membangun dan menjalin hubungan untuk mencapai segmentasi pelanggan dalam memberikan value propositions. Saat ini cara yang dijalani oleh PT Internasional Golden Shipping melalui kontak pengaduan. Hal ini dibuktikan dari hasil wawancara kepada pihak perusahaan yang mempunyai jawaban yang sama "Jika pelanggan mempunyai keluhan atau masalah terhadap pelayanan perusahaan kami, kami menyediakan kontak pengaduan, email, hotline, ataupun dengan karyawan langsung kotak pengaduan yang di sediakan di counter." Dalam pembelian tiket kapal ini menggunakan jenis kontak secara langsung, sedangkan untuk pengaduan keluhaan konsumen menggunakan jenis kontak langsung \& tidak langsung.

\section{Customer Relationship}

Fungsi dari customer relationships ini adalah untuk mendapatkan pelanggan baru dan mempertahankan pelanggan lama dan menawarkan jasa kepada pelanggan. Proses pengelolahan yang dibangun oleh PT Internasional Golden Shipping adalah hubungan secara personal sehingga konsumen dapat merasakan pelayanan yang ramah dari karyawan saat melakukan transaksi pembelian tiket di counter. Selain itu untuk pelanggan tetap setiap hari raya seperti hari raya idul fitri sering kali memberikan bingkisan serta kartu ucapan selamat hari raya kepada pelanggan tetap.

\section{Revenue streams}

Revenue streams atau aliran dana masuk menggambarkan bagaimana perusahaan Internasional Golden Shipping memperoleh uang dari setiap segmennya, yaitu dari penjualan tiket kapal.

\section{Key resource}

Key resource menggambarkan aset terpenting yang menentukan keberhasilan perusahaan pelayaran dalam mengoperasikan model bisnis. Hal ini dibuktikan dari hasil wawancara kepada Ibu Fitania "Saat ini yang dimiliki PT Internasional Golden Shipping adalah SDM yang masih terbatas jumlahnya, kantor pelabuhan, alat operasional berupa kapal.

\section{Key activities}

Merupakan aktivitas utama yang dilakukan dalam satu perusahaan atau organisasi. Di perusahaan ini adalah kegiatan utama perusahaan adalah penjualan tiket kapal.

\section{Key partnership}

Merupakan mitra kerjasama perusahaan pelayarandalam mengoperasikan organisasi, saat ini dengan keterbatasan sumber daya perusahaan tetap membina dan menjaga hubungan baik antara mitramitra perusahaan, adapun mitra dari PT Internasional Golden Shipping saat ini adalah Supplier yaitu dari PT Bandar Victori Shipyard pemasok perlengkapan kapal berupa suku cadang. Kemudian untuk bahan bakar minyak atau BBM perusahaan menggunakan solar untuk bahan bakar minyak melakukan bunker di Malaysia karena kualitas bahan bakar minyak disana lebih baik dengan harga mengikuti kurs jual beli minyak dunia. Perusahaan juga membina kerja sama dengan PT Mitra Tunas Utama untuk menitipkan penjualan tiketnya.

\section{Cost structure}

Struktur biaya yang dikeluarkan oleh PT Internasional Golden Shipping untuk sumber daya manusianya dan biaya operasional. Karakteristik cost structure PT Internasional Golden Shipping terbagi menjadi 2 yaitu fixed cost ( beban gaji karyawan, beban umum dan adminsitrasi, beban bunga beban seaport tax) variable costs (bahan bakar minyak). 


\section{B. Anlisis SWOT}

Setelah mendapatkan potret bisnis model kanvas yang terjadi saat ini, maka selanjutnya melakukan analisis dengan melihat ancaman dan peluang yang terjadi di lingkungan perusahaan terhadap kekuatan dan kelemahan perusahaan saat ini, adapun hasil analisis SWOT tersebut terangkum dalam tabel di bawah ini. yang dimiliki perusahan ini sebagai satu-satunya perusahaan jasa angkut yang memiliki rute BatamJohor dengan memberikan program menarik, ancaman dalam perusahaan ini adalah munculnya pesaing yang baru ataupun yang sama.

\section{Value propositions}

Kekuatan dari value proposition ini adalah PT Internasional Golden Shipping merupakan perusahaan yang memiliki satu- satunya rute dari Batam-Johor di Indonesia, tetapi perusahaan ini hanya memiliki akses sandar di batam centre saja seharusnya ia memiliki 2 akses tempat sandar lain dibatam seperti di Harbourbay dan Sekupang dan hal inilah yang merupakan kelemahan PT Internasional Golden Shipping yang seharusnya bisa mendapatkan konsumen yang lebih banyak lagi yang akan meningkat pendapatan bisnis. Dalam keadaan ini PT Internasional Golden Shipping memiliki sebuah bentuk ancaman dari perusahaan lain untuk menyaingi bisnis ini dengan cara meniru atau memiliki rute yang sama yang menjadi unggulan dari perusahaan ini.

\section{Channels}

Kekuatan dari PT Internasional Golden Shipping dalam kekuatan channel memiliki respon yang cukup baik dalam menanggapi pengaduan konsumennya yaitu melalui telfon dan kotak saran ataupun langsung dengan karyawan namun tidak didukung dengan jumlah kualitas dari SDM yang baik hal ini menjadikan sebuah kelemahan bagi perusahaan jasa angkut ini. Peluang dari channel perusahaan ini ialah pada masa sekarang ini telah berkembangnya media internet, aplikasi seperti Facebook, Twitter dll dan komunikasi yang menjadi peluang untuk memudahkan konsumen untuk berhubungan dengan perusahaan. Ancaman dari aspek channels ialah persaingan antar perusahaan yang lebih cepat meningkatkan kemampuan mengelola channels. mendukung kekuatannya yaitu kurangnya sarana promosi yang seharusnya bisa di manfaatkan untuk menarik konsumen lebih banyak lagi. Adapun peluang

PT IGS memiliki customer segment yang Kantor PT Internasional Golden Shipping yang terletak di pusat kota memudahkan konsumen untuk membeli tiket tetapi perusahaan ini memiliki titik lemah yang tidak 


\section{Customer relationship}

Kekuatan dari customer relationships adalah hubungan penyedia jasa angkut yaitu selaku perusahaan memiliki konsumen yang setia yang ditarik minatnya melalui fasilitas yang diberikan oleh perusahaan namun hal ini tidak didukung dengan kurangnya sarana promosi dari perusahaan untuk memasarkan nilai jual perusahaan akan tetapi sebaiknya bisa dijadikan peluang untuk dapat bekerjasama dengan pelanggan untuk membuat ide baru untuk memajukan perusahaan. Kemudian dengan adanya kelemahan tersebut memiliki ancaman bagi perusahaan itu sendiri yaitu dengan adanya pesaing yang menawarkan program yang lebih baik.

\section{Revenue streams}

Kekuatan dari revenue streams yang menjadi modal utama perusahaan ialah pendapatan dari penjualan tiket saja dan kelemahannya tidak lain ialah hanya mengandalkan satu arus pendapatan yaitu penjualan tiket, dari peluang ini seharusnya bisa menciptakan peluang arus pendapatan lain seperti penjualan aksesoris, minuman ataupun snack baik itu di counter tiket ataupun di dalam kapal. Ancamannya dikarenakan hanya memiliki satu arus pendapatan sehingga meningkatkan resiko kehilangan yang lebih besar.

\section{Key resources}

Kekuatan yang ada dalam key resources yang paling terpenting adalah adanya SDM yang professional dan berkualitas walaupun tidak didukung dengan jumlah yang banyak tetapi dapat menjalankan aktivitas bisnis jasa angkut namun hal ini tidak didukung dengan kurangnya sarana promosi dari perusahaan untuk memasarkan nilai jual seharusnya perusahaan dapat meningkatkan jumlah karyawannya karena memungkinkan konsumen untuk berpindah ke jasa angkut yang lain.

\section{Key activities}

Kekuatan yang ada dalam key activities adalah perusahaan sudah menjalankan aktivitas penjual tiket seefesien mungkin walaupun tidak didukung adanya aktivitas pemasaran yang merupakan kelamahan dari perusahaan ini sendiri seharusnya SDM yang ada mampu menciptakan sebuah promosi untuk mendukung pemasaran karena bila tidak adanya pemasaran tersebut, maka akan menimbulkan ancaman yaitu harga tiket perusahaan satu dengan yang lain akan bersaing.

\section{Key partnership}

Kekuatan dari key partnerships adalah kedekatan karyawan perusahaan khususnya pada bagian karyawan terhadap konsumen dan mitra kerjanya terjalin dengan baik, sehingga memberi peluang untuk perusahaan yakni kemudahan bekerjasama kepada konsumen ataupun supplier karena citra perusahaan yang baik di mata konsumen dan supplier, dan ketergantungan kepada individu untuk mengelola partnership ini menjadikan ancaman bagi perusahaan.

\section{Cost structure}

Kekuatan yang ada dalam cost structure pada perusahaan ini pemodalan cukup kuat dari owner tetapi dari modal yang banyak terdapat pengeluaran biaya yang meningkat seperti BBM kapal, atau pun biaya operasional lainnya, seharusnya perusahaan bisa melakukan negoisasi ke supplier untuk memperoleh discount.

\section{Kesimpulan Dan Saran}

Kesimpulan model bisnis yang telah dijalankan di PT Internasional Golden Shipping (PT IGS) berdasarkan model bisnis kanvas dijabarkan dalam sembilan elemen yaitu:

a) Elemen pertama customer Segment terbukti bahwa PT Internasional Golden Shipping segmentasinya dari segi ekonomi lebih mengarah ke kalangan menengah keatas.

b) Elemen kedua yaitu Value Proposation terlihat dari keunggulan yang dimiliki perusahaan ini yaitu satu-satunya perusahaan kapal yang dapat bersandar di Johor Pasir Gudang. 
c) Elemen ketiga yaitu Channels yang dijalankan oleh Perusahaan ini adalah membangun dan menjalin hubungan baik dengan konsumen dan menampung keluhan konsumennya dengan menyediakan sarana kotak pengaduan.

d) Elemen keempat yaitu Customer Relationships yang dibangun oleh perusahaan dengan berhubungan secara personal sehingga konsumen pun dapat merasakan pelayanan yang ramah dari karyawan saat melakukan transaksi ataupun keluhan.

e) Elemen kelima yaitu Revenue streams terbukti dari penghasilan yang di dapat dari perusahaan ini hanyalah dari hasil penjualan tiket kapal saja.

f) Elemen keenam dari key resources dijelaskan bahwa aset yang sangat penting yang menentukan keberhasilan dari perusahaan ini adalah SDM yang berkualitas, dan alat operasional berupa kapal.

g) Untuk elemen ketujuh Key activities terlihat dari aktivitas utama yang dilakukan oleh PT Internasional Golden Shipping adalah melayani konsumen dalam transaksi penjualan tiket kapal.

h) Untuk elemen selanjutnya yaitu Key Partnership pada PT Internasional Golden Shipping dengan keterbatasan sumber daya manusia perusahaan selalu membina dan menjaga hubungan baik antara mitra bisnis perusahaannya.

i) Dan elemen terakhir yaitu Cost structure dibuktikan bahwa biaya yang sering dikeluarkan pada perusahaan adalah fix costs (biaya gaji karyawan, biaya pengeluaran BBM dll)

\section{Saran}

Dari hasil penelitian yang telah dilakukan, terdapat beberapa saran yang dapat disimpulkan kepada PT Internasional Golden Shipping.
1. Mengimplementasikan strategi yang direkomendasikan pada PT Internasional Golden Shipping yaitu pada ke sembilan elemen bisnis model kanvas agar dapat mencapai keunggulan dalam bersaing.

2. Berfokus mengantisipasi dan mengatasi ancaman pada tiga elemen bisnis model kanvas yaitu customer segments, value proposition dan revenue streams karena dari hasil analisis SWOT ketiga elemen tersebut memiliki ancaman yang cukup kuat.

\section{Ucapan Terimakasih}

Alhamdulillahi robbi'alamin, puji syukur kehadirat Allah SWT atas segala rahmat dan hidayah-Nya sehingga penulis dapat menyelesaikan skripsi ini dengan baik. Tidak lupa juga penulis sampaikan rasa terima kasih yang tak terhingga kepada kedua orang tua mamah dan papah. Seluruh Dosen dan Staff Administrasi Bisnis, para senior, sahabat, dan temanteman seperjuangan, serta semua pihak yang tidak dapat disebutkan satu persatu, terima kasih atas segalanya, suka dan duka yang telah mewarnai kehidupan perkuliahan hingga selesainya skripsi ini.

\section{DAFTAR PUSTAKA}

Aziz, N. F. (2015). Comparison of business model canvas (BMC) among the hree consulting companies. Journal of computer science and information technology research. Internasional Islamic University Malaysia, Vol. 3, Issue 2, pp. 462-471.

Chesbrough, H. W. (2006). Open Business Models: How to thrive in The New Innovation Landscape. Boston: Harvard Business School Press.

Damardjati, R.S. (2005). Istilah-istilah Dunia Pariwisata. Jakarta: PT Pradnya Paramitha.

David, Fred R, 2006. Manajemen Startegis. Edisi Sepuluh, Penerbit Selemba Empat, Jarkata.

Jogiyanto, 2005, Sistem Informasi Strategik untuk Keunggulan Kompetitif, Penerbit Andi Offset, 
Yogyakarta.

Kosasi, V. M., (2015). Analisis dan evaluasi model bisnis pada pantai Seafood Restaurant dengan pedekatan business model canvas. Jurnal Manajemen Bisnis, Program Studi Manajemen, Universitas Kristen Petra, Vol 3, no 1.

Levy, M. (2001). The principles of highly successful business models: Using the value framework. ECnow.com, Inc.

Ostelwalder, A. dan Pigneur, Y.(2009). Business model generation. John Wiley \& Sons, Inc., Hoboken: New Jersey.

Priyono, F. (2005). Analisis Penerapan Business Model Canvas Pada Toko Moin Collection. Jurnal Manajemen Bisnis, Program Studi Manajemen, Universitas Kristen Petra, Vol 3, no 2.

Purba, H. (2005). Hukum Pengangkutan di Laut, perspektif dan praktek, Medan: Pustaka Bangsa Pres, 2005. 